\title{
Découverte de nouveaux virus des hépatites, les "GBV": quelle est leur place et quel est leur pouvoir pathogène?
}

Lors de la dernière conférence internationale sur les agents antimicrobiens et la chimiothérapie (ICAAC) qui s'était tenue fin 1994 à Orlando (USA), Bradley [1, 2], du C.DC: d'Atlanta (GA, USA), s'est dit persuadé que même s'il ne pouvait pas faire de révélations, montrer des photographies en microscopie électronique ou des génomes, on allait découvrir à brève échéance de multiples nouveaux virus des hépatites, certains nus et d'autres enveloppés, à l'origine d'hépatites aiguës ou chroniques, entérofécales ou parentérales.

Un certain nombre d'indices ou d'informations confidentielles laissaient penser qu'il existait des virus des hépatites non A-B-C-D-E; déjà pour ceux qui restaient à découvrir, des sigles étaient proposés, F, (;... voire X, Y, Z.

Plusieurs arguments plaident en faveur de l'existence de nouveaux agents des hépatites non étiquetés, à transmission, soit entérique, soit parentérale. Ainsi, selon la zone géographique, les hépatites chroniques non A-E représentent $5 \%$ des cas aux États-Unis et $20 \%$ voire $27 \%$ des cas en Chine.

Il restait donc, après avoir éliminé tous les virus connus dits "des hépatites" et ceux qui peuvent entraîner occasionnellement des atteintes hépatiques (Herfes rirus notamment), à rechercher d'autres virus et à préciser leur modalité de transmission ainsi que leur pouvoir pathogène.

Depuis cinq ans, outre les nouveaux variants ou génotypes des virus $\mathrm{B}, \mathrm{C}$ et $\mathrm{E}$, un certain nombre de "nouveaux virus" ont été suspectés ou décrits [3-6] à $\mathrm{ADN}$ ou à $\mathrm{ARN}$, nus ou enveloppés, notamment apparentés aux paramyxovirus [7] et aux togavirus [8].

Des révélations importantes ont été faites lors d'une réunion organisée par les laboratoires Abbott qui vient de se tenir à Washington (DC, USA) [9] : un nouveau groupe de virus "des hépatites" a été décrit dans le détail avec organisation et séquençage génomique, méthodes de diagnostic et même avec enquêtes sérologiques préliminaires; il s'agit des GBV ou GB hepatitis virus dont trois types ont été décrits simultanément: GBV-A, GBV-B [10] et GBV-C.

Le premier isolat (BB a été obtenu à partir du sang d'un chirurgien européen de 34 ans qui avait présenté un ictère (GB sont les initiales du malade) ‘́ un prélèvement sanguin pratiqué à la phase aiguë de la maladie a été inoculé avec succès à des singes tamarins ; certains animaux ont présenté une maladie avec montéc des transaminases. Après un travail considérable ayant nécessité plus de dix passages successifs sur ces animaux et l'exclusion de tous les virus connus, il a été possible, en utilisant des techniques complexes d'amplification, de clonage et de séquençage, d'identifier non pas un virus mais, dans un premier temps, deux virus GBV-A et GBV-B [10], puis plus tard d'en identifier un troisième, GBV-C, à partir d'un patient nord-américain ( $T$. Leary, laboratoires Abbott, IL, USA) [9]. Ces trois virus sont des virus enveloppés ayant un ARN (simple brin +) avec de multiples cadres ouverts de lecture, apparentés, comme le virus de l'hépatite C (VHC), aux flavivirus (figure 1); ils possèdent, comme lui [11], une organisation génomique comportant des gènes structuraux à l'extrémité 5', de cœur, d'enveloppe $(\mathrm{E} 1, \mathrm{E} 2)$ et des gènes non structuraux avec, vers l'extrémité 3', les zones NSl, NS2, NS3, NS4, NS5.

Aux deux extrémités figurent des séquences non codantes.

Ces trois virus GBV-A, GBV-B et GBV-C possèdent respectivement un génome de 9493, 9143 et 9034 nucléotides codant respectivement pour 2972, 2864 et 2905 acides aminés. Pour mémoire, le virus de l'hépatite C, VHC-1, a un génome de 9401 nucléotides et code pour 3011 acides aminés. Comme pour ce virus, on a pu montrer que la NS3 des GBV code pour une protéase et une hélicase, et la NS5 pour la réplicase.

Le pourcentage d'analogie des séquences peptidiques de ces virus du groupe $\mathrm{GB}$ avec le virus de l'hépatite C (VHC-1) ou ses différents génotypes (\% d'identité des acides aminés) est faible: $26 \%$ pour le GBV-A, $32 \%$ pour le GBV-B et $29 \%$ pour le GBV-C.

Le pourcentage d'analogie est également faible entre les membres du groupe $\mathrm{GB}: \mathrm{A} / \mathrm{B}=27 \%, \mathrm{~A} / \mathrm{C}=48 \%$, $\mathrm{B} / \mathrm{C}=28 \%$, mais cela n'empêche pas des réactivités immunologiques croisées au sein du groupe GBV. L'analyse phylogénétique des génomes des $\mathrm{GBV}$, des VHC et d'autres flavivirus montre que les GBV n'appartiennent pas à l'ensemble des VHC, que les GBV-A et $\mathrm{C}$ sont plus proches entre eux qu'ils ne le sont du GBV-B sur la base des séquences des hélicases et polymérases; par ailleurs, les GBV sont plus proches des VHC que des autres flavivirus connus.

Après analyse génomique et prédiction épitopique, ont été réalisés des 
clonages de gènes et expression chez Escherichia coli des protéines dont on pouvait penser qu'elles étaient immunogènes (T. Pilot-Matias, laboratoires Abbott, IL, USA); ont été ainsi obtenues différentes protéines: 4 pour GBV-A, 3 pour GBV-B, 3 pour GBV-C, concernant essentiellement des protéines non structurales. Ces protéines recombinantes ont permis de développer des tests immunoenzymatiques qui ont été utilisés dans des enquêtes sérologiques à l'aide de tests ELISA de dépistage, puis après vérification de la répétabilité de la réaction positive, utilisation de tests complémentaires (Western blot, recherche d'IgM, voire recherche de génome par RT-PCR).

Des enquêtes préliminaires, mais déjà de grande ampleur, ont porté sur différentes populations. Elles montrent une large diffusion de ces virus (G. Dawson, laboratoires Abbott, IL, USA). Chez les donneurs de sang américains ; la prévalence globale GBV-A-B-C est de $2 \%$, cette prévalence s'élève à près de $12 \%$ chez les drogués par voie intraveineuse et à $14 \%$ chez les polytransfusés. Dans les dons du sang en Afrique de l'Ouest, le taux s'élève à près de $27 \%$.

Une première investigation a porté sur des sujets présentant des hépatites d'étiologie inconnue: la prévalence globale des GBV y est de $10,6 \%$ (anti-GBV-A : 4,5\%, GBV-B : $6,6 \%$, GBV-C : $5,5 \%$ ), avec des différences considérables selon les zones géographiques : 4,8 \% au Japon, $7,4 \%$ aux États-Unis, $10,7 \%$ en Nouvelle-Zélande, $17,4 \%$ en Europe et $48 \%$ en Afrique de l'Ouest.

Ces enquêtes sérologiques ont été complétées dans d'autres sites par la recherche du génome par PCR chez des sujets positifs et négatifs pour la sérologie anti-GBV; alors que les recherches de génome sont presque toujours en échec chez les séronégatifs, on retrouve près de $20 \%$ de PCR positives chez les sujets séropositifs, signant une virémie [12]. Il apparaît que cette virémie peut persister durant des mois, voire des années, indiquant donc l'existence de portages chroniques, mais la durée de la persistance des anticorps n'est pas

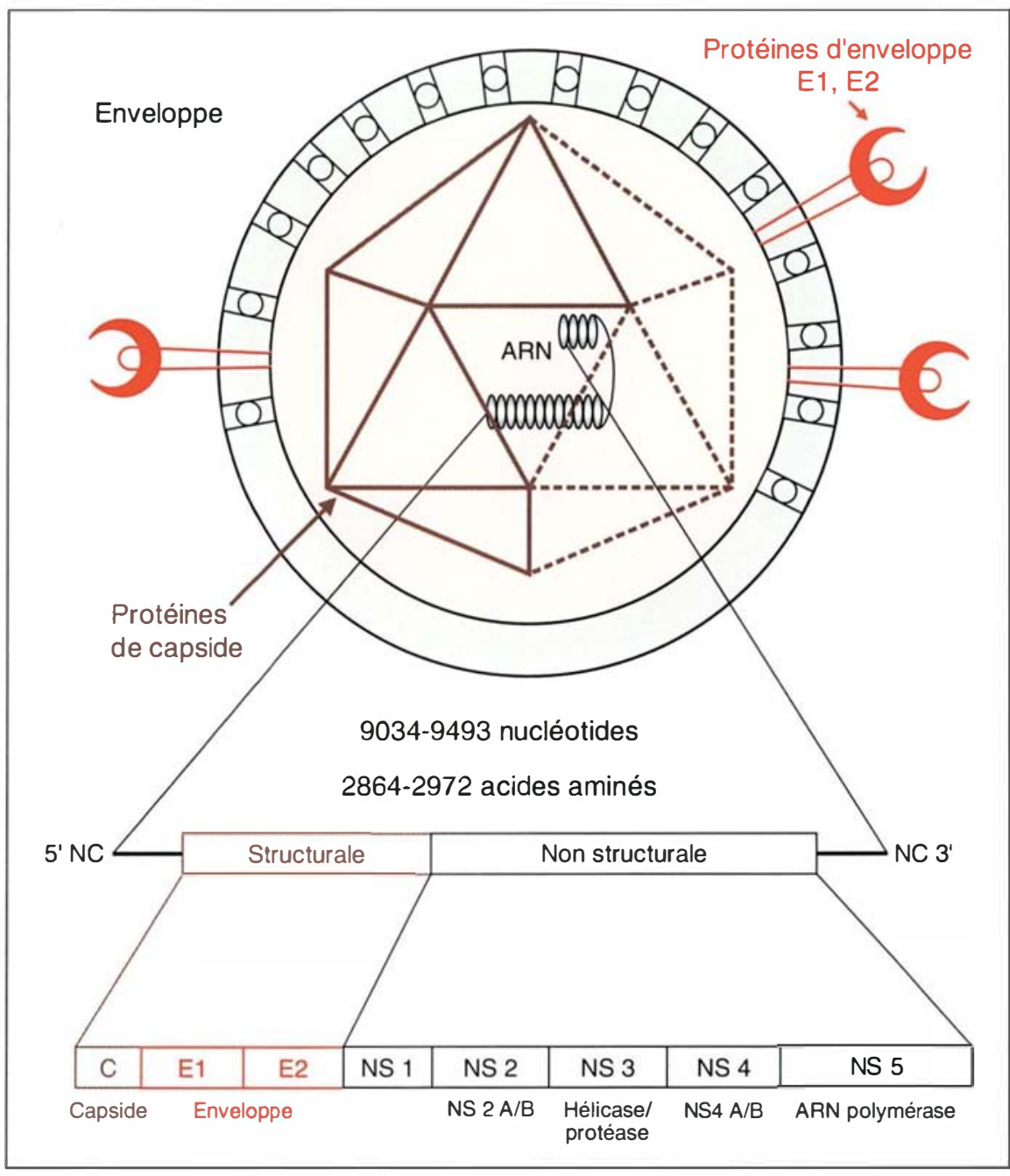

Figure 1. Représentation schématique et organisation génomique de nouveaux virus des hépatites, les "GB " virus, apparentés aux Flavivirus. Ce sont des virus enveloppés ayant un ARN (simple brin + ) avec de multiples cadres ouverts de lecture, apparentés, comme le virus de l'hépatite C (VHC), aux Flavivirus; leur organisation génomique comporte des gènes structuraux à l'extrémité 5', de cœur ou capside et d'enveloppe (E1, E2), et des gènes non structuraux avec, vers l'extrémité 3', les zones NS1, NS2, NS3 (codant pour une hélicase et une protéase), NS4, NS5 (codant pour une ARN polymérase). Aux deux extrémités figurent des séquences non codantes. Les trois virus GBV-A, GBV-B et GBV-C possèdent, respectivement, un génome de 9493, 9143 et 9034 nucléotides codant pour 2972, 2864 et 2905 acides aminés. NC : non codant.

Les résultats présentés lors du symposium mériteront d'être examinés dans le détail lors de leur publication qui est imminente [11], mais ils représentent une avancée très importante concernant les connaissances sur les nouveaux virus des hépatites non A-E. Il apparaît désormais indispensable d'explorer plus avant le rôle réel de ces virus à transmission essentiellement parentérale, et qui semblent assez répandus, dans la genèse des hépatites chroniques. Sont-ils des agents pathogènes à part entière, de simples virus associés ou des cofacteurs? Il est trop tôt pour le savoir.

Si le virus GBV-B entraine une virémie, une élévation de transaminases et l'apparition d'anticorps chez les 
Tamarins, on trouve pour le GBV-A une virémie sans élévation de transaminases, ni d'ailleurs de synthèse d'anticorps. Ce dernier virus n'aurait peut-être pas comme site de réplication principal les hépatocytes, alors que le B est présent dans ces cellules. Il importera de rechercher génome et anticorps anti-GBV dans les hépatites chroniques non A-E et d'étudier les séquences: infections, séroconversions, suivis cliniques, biologiques et virologiques, avant de connaître la place réelle de ces virus en pathologie, en fonction des zones géographiques.

Après cette étape, il conviendra d'évaluer la nécessité de mettre en place un dépistage sérologique chez les donneurs de sang et de mettre en œuvre une recherche virale chez les patients présentant des hépatites aiguës ou chroniques non $\mathrm{A}-\mathrm{E}$; quoi qu'il en soit, si les résultats présentés se trouvent confirmés, il s'agit là d'une avancée très importante dans le domaine de la virologie et du monde des virus des hépatites

\section{RÉFÉRENCES}

1. Bradley D. Non-ABCDE hepatitis : evi dence for the existence of another infectious agent. 34th International Conference on Antimicrobial Agents and Chemotherapy (ICAAC), Orlando, 1994.

2. Editorial. Another mysterious hepatitis virus may be lurking. ASM News 1995 ; 61: 12 .

3. Craske J. Hepatitis C and non-A, non-B hepatitis revisited: hepatitis $\mathrm{E}, \mathrm{F}$ and $\mathrm{G} . J$ Infect 1992 ; 25 : 243-50.

4. Deka N, Sharma MD, Mukerjee R. Isolation of the novel agent from stools samples that is associated with sporadic non-A, nonB hepatitis. J Virol 1994; 68: 7810-5.

5. Editorial. The $A$ to $F$ of viral hepatitis. Lancet 1990 ; 336 : 1158-60.

6. Editorial. Hepatitis G. Lancet 1991; 337 : 1070 .

7. Phillips MJ, Bledis LM, Pourcell S, et al. Sporadic hepatitis with distinctive pathological features, a severe clinical course, and paramyxovirus features. N Engl J Med 1991 p24: 455-60.

8. Fagan EA, Ellis DS, Tovey GM, et al. Togalike virus as a cause of fulminant hepatitis attributed to sporadic non-A, non-B. J Med Virol $1989 ; 28: 150-5$.
9. Meeting on "New Hepatitis viruses". Washington, 7 avril 1995.

10. Simons JN, Pilot-Matias TJ, Leary TP, et al. Identification of two flavivirus - like genomes in the GB hepatitis agent. Proc Nat Acad Sci USA 1995; 93 : 3401-5.

11. Trepo C. Identification du virus de l'hépatite C (VHC) : un progrès décisif pour la santé publique. médecine/sciences $1990 ; 6$ : 98-107.

12. Schlauder GG, Dawson GJ, Simons NJ, et al. Molecular and serologic analysis in the transmission of the GB hepatitis agents. I Med Virol 1995 ; 46 : 81-90.

\section{François Denis \\ Thierry Nicot}

Service de bactériologie-virologie-hygiène. CHU Dupuytren, 87042 Limoges Cedex, France.

TIRÉS À PART

F. Denis. 